\title{
Dear Readers, Authors, and Prospective Authors
}

\author{
(C) Springer-Verlag 2011
}

We are continuing to make changes, hopefully always for the better, as the number of manuscripts submitted for publication in this journal continues to increase. We are attempting to smooth the process of getting papers reviewed, edited, and printed. Although those of you who have never submitted a manuscript are not aware of this, we inserted a quality control step in our editorial procedures a couple of years ago when we had a problem with figures being published that were not of the highest quality. Somehow, twice, after the authors had made changes to the figures in response to recommendations by the editors or reviewers, the old figures were published instead. Of course, the authors had been sent electronic proof copies to look at, but they had looked at the text, not the figures. So we ended up republishing the papers, with the correct figures, and our apologies, though we never figured out how the process had broken down. As a makeshift solution, we instituted the rule that after the papers received final approval by me, it was sent again to our graphics editors, who would check to make sure that the right figures, with the correct high-resolution images, were the ones attached to the manuscript. With some trepidation, we are now eliminating that step and indeed the position of graphics editor. Instead, the graphics editors are being made associate editors, spreading the workload somewhat, and the former graphics editors are preparing instructions that all of the associate editors, and I, will attempt to follow to ensure that the quality of the figures does not slip. Ideally, this transition will happen smoothly, between this issue and the next, and those of you who are readers will never notice a thing. But I ask those of you who are authors to be extra vigilant in following our journal's guidelines, which are available at: http://www. IMWA.info/notes-for-contributors.html, and in checking your proof copies when they are e-mailed to you.

Our new associate editors are, in addition to Alex Waterhouse (who I welcomed in this spot last month), Romy Matthies (our former graphics editor), and Charlotte Braungardt (who goes by Charly) of the University of Plymouth, who was our graphics editor-in-training. We have also added the esteemed David Blowes, of the University of Waterloo, Lena Alakangas from Luleå University of Technology, and Rosa Cidu of the University of Cagliari to our International Editorial Board. You will find

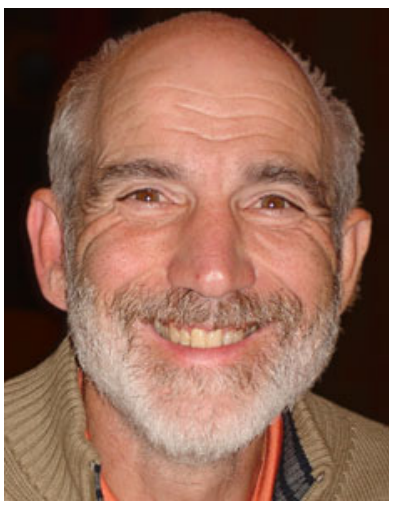

their contact information on the inside front cover of this journal; feel free to e-mail them and thank them for their efforts.

We are also going to be increasing the number of pages that we print in each issue. One of the nice aspects of our journal has been the relatively fast turnaround between when a manuscript is accepted and published online to the time that it appears in print. While some journals take a year or more to do this, we have always been able to accomplish that in 6 months or less. However, as the number (and quality) of papers submitted has increased, our backlog of accepted manuscripts has begun to creep up as well. To combat this, we will be publishing one or two additional papers per issue, starting with this issue. So you will be receiving more for your money! At some point, we may have to increase the annual cost of your membership/ subscription but I am confident that we will remain the best value available anywhere in the technical journal literature, thanks to all of the great people who voluntarily spend their spare time seeing to it that these papers get written, reviewed, and edited, without reimbursement other than your encouragement and praise.

I look forward to seeing all of you at the 2011 IMWA Congress in Aachen, Germany, in September.

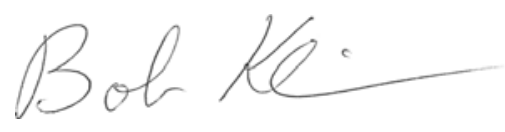

Bob Kleinmann, Editor-in-Chief 